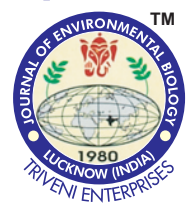

\title{
Utilizing Borassus flabellifer sprout peel sugars by Pseudomonas fluorescence for degradation of textile effluent
}

\section{Authors Info \\ Joyce Hellen Sathya ${ }^{1,2 *}$, \\ N. Franklin², N. Balaji', \\ S. Selvaraj ${ }^{2}$ and \\ M. Seenuvasan ${ }^{3,4}$ \\ 'Department of Biotechnology, \\ Prathyusha Engineering College, \\ Chennai - 602 025, India \\ ${ }^{2}$ Department of Biotechnology, \\ Madha Engineering College, \\ Chennai - 600 069, India \\ ${ }^{3}$ Department of Petrochemical \\ Engineering, SVS College of \\ Engineering, Coimbatore- 642 109, \\ India \\ ${ }^{4}$ Department of Chemical \\ Engineering, Hindusthan College \\ of Engineering and Technology, \\ Coimbatore-641 032, India}

*Corresponding Author Email : joycehellensathya@gmail.com

\section{Edited by \\ Professor G. Manjula}

Reviewed by

Dr. P. Kannan Pownsamy

Dr. K. Sathish Kumar

\section{Abstract}

Aim : The present investigation deals with the extraction of sugars from tuber peels of Borassus flabellifer and their subsequent utilization for the growth of a bacterial isolate. The study also aims to degrade the textile effluent using $B$. flabellifer sprout peel sugar supplemented bacterial isolate.

Methodology : The isolate was screened from a textile effluent and was identified as Pseudomonas fluorescence. The sugar peels were pretreated by dilute acid hydrolysis and extracted sugars were used as supplement for the growth of $P$ seudomonas fluorescence. The textile effluent was treated with the bacterial isolate for degradation. The decolorization and degradation was monitored using UV-Visible spectrophotometry, Fourier Transform Infrared (FT-IR) Spectroscopy and Gas Chromatography With Mass Spectrometry (GC-MS).

Results : B. flabellifer sprout peel sugar was supplemented as a macronutrient to support the growth of Pseudomonas fluorescence for the degradation of textile effluent. Higher decolorization efficiency (95\%) within 7 days under aerobic condition at $\mathrm{pH}-7.0$ and temperature $35^{\circ} \mathrm{C}$ was achieved.

Interpretation: The present study showed that the growth of Pseudomonas fluorescence was possible in tuber peel extracted sugars which was used as a carbon source. The bacteria grown in tuber peel extracted sugars was able to decolorize and degrade the textile effluent.

Key words : Borassus flabellifer, Degradation, Extracted sugars, Pseudomonas fluorescence
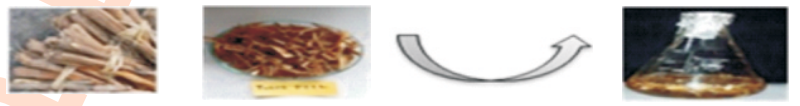

Pretreatment and hydrolysis

\section{Palmyra sprouts}

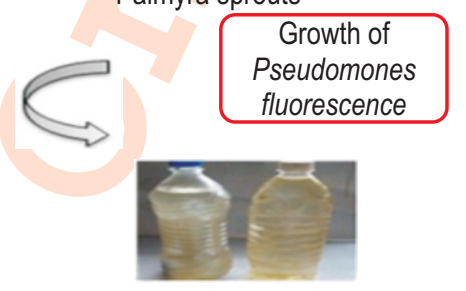

Textile effluent

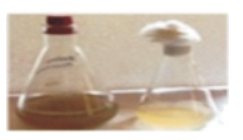

Textile effluent degradation

How to cite : Sathya, Joyce Hellen, N. Franklin, N. Balaji, S. Selvaraj and M. Seenuvasan: Utilizing Borassus flabellifer sprout peel sugars by Pseudomonas fluorescence for degradation of textile effluent. J. Environ. Biol., 40, 736-741 (2019). DOI : http://doi.org/10.22438/jeb/40/4(SI)/JEB_02 


\section{Introduction}

Currently research for suitable biomass to extract sugars as a carbon source for the growth of microorganisms is underway. Sugars present in the lignocellulosic biomass are tightly packed into crystalline cellulose polymers. These play a major role in the bioconversion of lignocellulosic biomass (Marcel Dekker, 2005; Peters, 2007; Lange,2007; Binder and Raines, 2009) which acts as substrates. Utilization of these raw materials yields reduced amount of sugars. It is also accompanied by other factors like presence of furfural derivatives which inhibits the growth and cost of hydrolysis. Pre-treatment methods to extract sugars are achieved by chemical and biological processes (Chaturvedi and Verma, 2013; Singh et al., 2016). Most often chemical methods namely hydrolysis using concentrated or dilute acid are employed to delignify the biomass. The major advantage of acid hydrolysis is to increase the delignification rate faster than enzyme hydrolysis by penetrating the biomass to release sugars from the cellulosic framework. In some cases, ionic liquids were used to hydrolyse the biomass for bioconversion by the action of enzymes. (Dadi, 2006 ; Kilpelainen et al., 2007 and Singh et al., 2009). Ionic liquids produce lesser amount of glucose ( $\mathrm{Li}$ and Zhao, 2007; Li et al., 2008; Rinaldi et al., 2008; Vanoye et al., 2009 and Sievers et al., 2009) whereas through hydrolysis of cellulosic biomass with concentrated acids and solvents high yield of glucose was obtained. On account of these factors lignocellulosebased biomass are selectively used for very few processes. To ensure that the utilization of hydrolyzed sugars does not inhibit microbial growth, the sugars derived from corn stover were supplemented with salts and the ethanologenic bacterium and yeast were grown (Binder et al., 2010). Several agro wastes sugarcane bagasse, rice straw, bio-waste, peels of cassava, starch (cassava tubers) potato and banana (Arapoglou et al., 2010; Benjamin et al., 2014) have been explored for their reducing sugars to use as feedstock in biofuel production. The use of acid hydrolyzed potato peels for the extraction of total reducing sugars (Bhattacharyya et al., 2013), cassava peel residues for its conversion into fermentable sugars (Souto et al., 2017), pseudostem (Seenuvasan et al., 2017) softwood (pine), hardwood (poplar, birch and beech), wheat straw and hemp (bast and harl) (Buzała et al., 2017) and Aloe vera rinds (Sathya et al., 2017) are also being bung exploited for raw material as an alternative to carbohydrates

Borassus flabellifer is a palm tree classified under Palmae family native to Africa. Palmyra sprout (known as Palmyra Tuber) is a sprout that grows on palmyra palms. The distribution of palmyra palms over the world is about 140 million. Tamil Nadu is a potential centre for the export of palm products. The growth and development of palm products industry is diversified in Tamil Nadu, India. Out of the estimated 8.59 cores of Palmyra in India, about 10 cores of Palmyra are grown in Tamil Nadu. The length of the shoot is between $12-15 \mathrm{~cm}$ before harvesting. Palmyra seed- shoot possess high starch content and are used in the preparation of palm spread and palm toffee (Churasiya et al., 2014). The use of Borassus flabellifer peels for the analysis of glucose has been reported (Sathya et al., 2017)

Sulphonated azo dyes are imposing a major threat to the aquatic life forms when discharged into the water stream. Proper treatment can reduce the risk of hazard to the live forms which are accompanied by biological treatments. The ability of bacterial strains that are able to degrade azo dyes under aerobic and anaerobic conditions has been extensively reported by many researchers. Bacterial strains that are able to degrade aromatic hydrocarbons have been repeatedly isolated, mainly from soil. These are usually Gram negative bacteria, most of them belong to the genus $P$ seudomonas.

Decolorization of Reactive blue 13 by Pseudomonas sp. under static conditions with efficiency of $83.2 \%$ has been reported (Lin et al., 2010). The growth of Pseudomonas fluorescence on starch hydrolysate for polyhydroxybutyrate production is been reported (Aremu et al., 2010). Pseudomonas desmolyticum NCIM2112 has been reported (Parte et al., 2013) to degrade sulphonate aromatic compounds. The efficiency of $P$ seudomonas aeruginosa for rapid decolourization of azo dye, Cibacron Red was reported recently (Fetyan et al., 2017). Palmyra sprout peels contain complex carbohydrate such as cellulose, hemicelluloses, lignin, etc. Pre treatment process such as acid hydrolysis followed by steam exposure can be used to degrade these complex carbohydrates to yield simple monosaccharides such as glucose. The extracted sugars are used as carbon source for the growth of Pseudomonas fluorescence, which are eminent sources for the degradation of pollutants. In view of the above, the present study focus on the use of Palmyra sprout peels for the extraction of fermentable sugars.

\section{Materials and Methods}

Chemicals required: Sulfuric acid $\left(\mathrm{H}_{2} \mathrm{SO}_{4}\right)$, sodium hydroxide $(\mathrm{NaOH})$, activated carbon, 3,5 di-nitro salicylic acid, phenol, potassium sodium tartarate, anthrone, peptone, yeast extract, sodium chloride and glucose were purchased from Nice Chemicals, Mumbai. All the chemicals were of analytical grade and were used without any further purification. Palmyra sprout (Borassus flabellifer) was purchased from the local market (Chennai, India). The peels were removed carefully. It was washed thoroughly with distilled water, dried under shade for 20 days and the peels were chopped to few $\mathrm{mm}$ thickness.

Collection of textile effluent: Textile effluent was collected from textile dyeing unit located at Sangu Nagar, Erode at Tamil Nadu, India. The effluent from the textile unit was collected in a one litre airtight plastic container. It was filtered to remove suspended particles and the entire experiment was carried out under sterile condition. 
Pretreatment and acid hydrolysis: To a $5 \mathrm{~g}$ of Palmyra sprout peels taken into a conical flask containing $200 \mathrm{ml}$ of water, $5 \%$ of sulphuric acid was added. The flasks were covered with aluminium foil and incubated for 2 days at room temperature. The sample was autoclaved at $121^{\circ} \mathrm{C}$ for $15 \mathrm{~min}$. The flasks were allowed to cool and the $\mathrm{pH}$ was adjusted to 7.4 with $\mathrm{NaOH}$. The sample was decolourized by passing it through No.1 Whatman filter paper containing activated carbon. The extracted glucose was determined by DNSA method (Miller, 1959) and the total carbohydrates were estimated by anthrone method (Trevelyan et al., 1952).

Screening and biochemical characterization of bacteria for textile effluent degradation: The microorganism was isolated from soil by performing a serial dilution of $10^{-2} \mathrm{U}$. The dilution was spread to agar plate and incubated overnight at $30^{\circ} \mathrm{C}$. The colonies obtained were isolated and pure culture was maintained. Periodic sub culturing was done to maintain the stock culture. The bacterial isolate was characterized biochemically by Voges proskauer test methyl red test, indole test, and gelatine hydrolysis test (Mac Faddin, 1980).

Preparation of bacterial inoculum using extracted glucose: Standard inoculum was prepared by inoculating subculture of Pseudomonas fluorescence from the stock culture in a $250 \mathrm{ml}$ conical flask containing $100 \mathrm{ml}$ nutrient broth containing: $5 \mathrm{~g} \mathrm{l}^{-1}$ Peptone; $1.5 \mathrm{~g} \mathrm{l}^{-1}$ Yeast extract; $5 \mathrm{~g} \mathrm{l}^{-1} \mathrm{NaCl}$ and $1 \mathrm{~g} \mathrm{I}^{-1}$ extracted glucose at $30^{\circ} \mathrm{C}$ for 3 days.

Analysis of metabolites: GC-MS analyses of the extracted metabolites were recorded by JEOL GCMATE II GC-MS with data system in a high resolution, double focussing instrument. An Agilent 6890 gas chromatograph was equipped with a straight deactivated $2 \mathrm{~mm}$ direct injector liner and a $15 \mathrm{~m}$ Alltech EC -5 column ( $25 \mu \mathrm{m}$ I.D. $25 \mu \mathrm{m}$ film thickness). A split injection was used for injecting sample and the split ratio was set to 10:1. The oven temperature was programmed to start at $35^{\circ} \mathrm{C}$, hold for $2 \mathrm{~min}$, then ramp at $20^{\circ} \mathrm{C}$ per min to $260^{\circ} \mathrm{C}$ and hold for 5 mins. Helium carrier gas was set to $2 \mathrm{ml} \mathrm{min}^{-1}$ flow rate (constant flow mode).

The decolorization activity was calculated using the formulae Giwa et al. (2011):

Decolorization activity $(\%)=\frac{\left(C_{0}-C_{t}\right)}{C_{0}} \times 100$

Where, $C_{0}=$ Initial absorbanc; $C_{t}=$ Observed absorbance
Decolourization efficiency of textile effluent was recorded using a UV-Visible spectrophotometer UV1800 (Shimadzu, Japan) between 200 and $800 \mathrm{~nm}$ with water as blank. IR spectra of purified compounds were recorded on a Bruker series FT-IR spectrometer using $\mathrm{KBr}$ pellets.

\section{Results and Discussion}

Use of raw materials for any fermentation process add on to the costs of upstream processing. Researchers are exploring new and potential raw materials for the extraction of major carbon sources to be used in the media which will support the growth of microorganisms. Glucose yield from the pseudo stem by cellulose mediated hydrolysis was observed to be much higher when compared with the acid hydrolysis (Seenuvasan et al., 2017). However, the fermentable sugars extracted from the Palmyra sprout peels in this study were identified to be a suitable raw material in favour of glucose by treatment with acid. The hydrolysed peels after neutralization were found to possess a sugar concentration of $1.27 \mathrm{mg} \mathrm{ml}^{-1}$ (Sathya et al., 2017).

Pure culture isolated from soil was identified by performing biochemical characterization. The morphology and colour of the colonies were examined under microscope and was identified as Gram negative. The results of bacterial isolate analysed biochemically by methyl red test, Vogues Proskauer, gelatin hydrolysing test and indole test is shown in Table 1. The results revealed that the identified bacteria was Pseudomonas fluorescence.

The growth was monitored by periodic sampling for every $24 \mathrm{hr}$. The growth of Pseudomonas fluorescence concomitantly increased in the extracted glucose from the Palmyra sprout peels on comparison with the standard nutrient broth. The advantage of using Pseudomonas fluorescence is moderate supply of glucose which is enough for their maximum growth.

The increase in decolorization activity versus incubation time reveals that the decolorization of effluent proceeds by the metabolic activity of the microorganism (Kumar et al., 2015, 2017; Vidhyadevi et al., 2014).

The mass spectrum of textile effluent before degradation eluted out of the column at different time intervals is shown in Fig.

Table 1: Biochemical characterization of isolated bacteria

\begin{tabular}{lll}
\hline Biochemical test & Identification & Results \\
\hline Gram staining & Pink color, rod shaped & Gram negative \\
Methyl red & No change & Gram negative \\
Indole & Nochange & Gram Negative \\
Vogues Proskauer & Change pale yellow color & Gram Positive \\
Gelatin hydrolysing & Gelatin is liquefied & Gram Positive \\
\hline
\end{tabular}




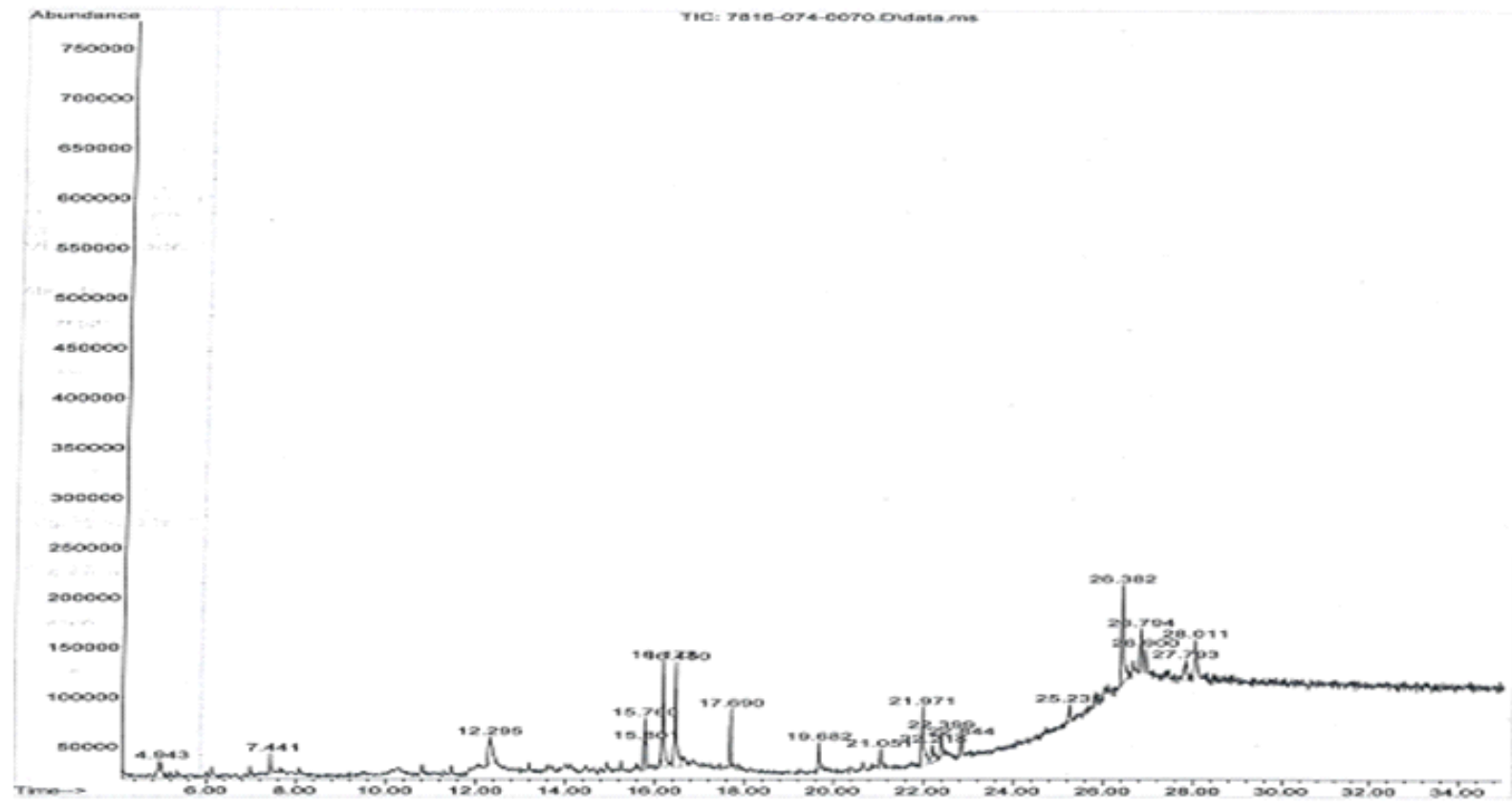

Fig. 1 : GC-MS analysis of textile effluent.

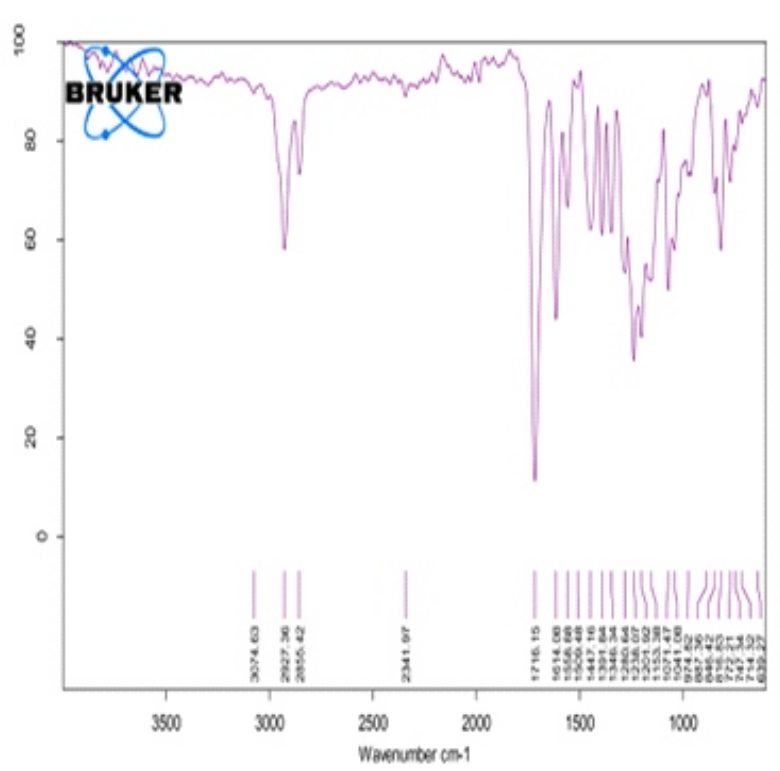

Fig. 2 : FT-IR spectra before effluent treatment.

1. It is evident that textile effluent contains toxic component like phthalic acid with retention time, Rt 16.17 min, methyl stearate Rt17.69 min, tenamfetamine Rt-1.679 min, aspartic acid Rt-25.234 min, which cause diarrhea, hepatotoxicity and neurotoxicity. The most abundant metabolite is benzoquinoline with Rt of 28.014 min.

The FT-IR spectra of textile effluent before and after degradation are shown in Fig. 2 and 3. The peaks at $3074 \mathrm{~cm}$

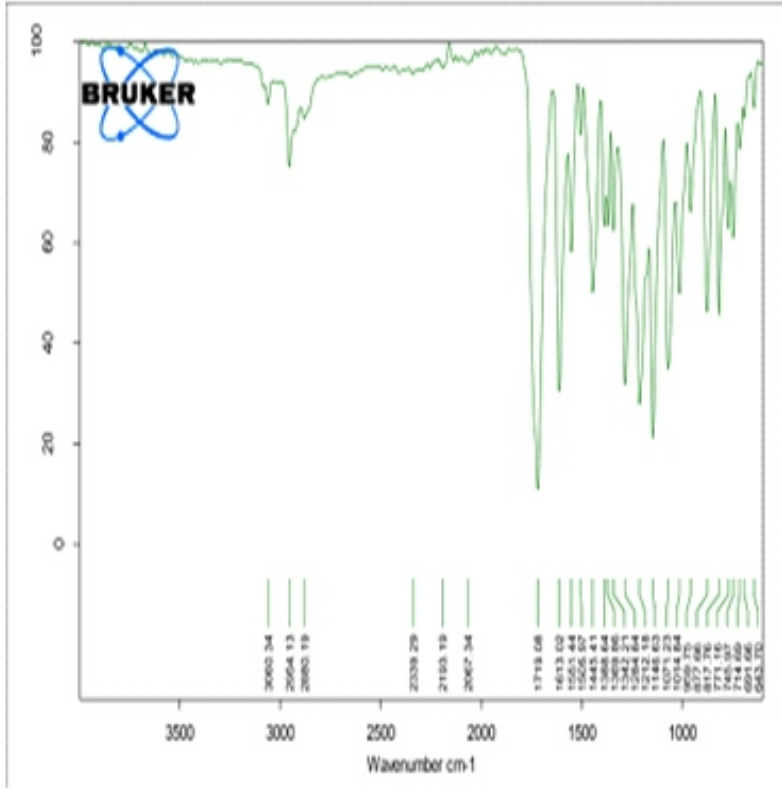

Fig. 3 : FT-IR spectra after effluent treatment.

${ }^{1}, 1614 \mathrm{~cm}^{-1}, 1346 \mathrm{~cm}^{-1}$ and $1280 \mathrm{~cm}^{-1}$ indicate the presence of $\mathrm{C}-\mathrm{H}$ stretch (aromatic) which is benzoquinoline, $\mathrm{N}-\mathrm{H}$ bend which is primary amine, $\mathrm{CH}$ rock (alkanes) and $\mathrm{C}-\mathrm{H}$ stretch (aliphatic amine). Corroborate the previous study degradation of AR88 into aliphatic and tertiary amines by appearance of the peak at 1643 $\mathrm{cm}^{-1}$ for $\mathrm{C}=\mathrm{C}$ stretch and peak at $1345 \mathrm{~cm}^{-1}$ for $\mathrm{S}=0$ stretch which indicated the presence of aromatic compounds (Kumar et al., 2017). 
Whereas, the FT-IR spectra of the effluent metabolites is shown in Fig. 3. The peaks obtained at $3060 \mathrm{~cm}-1,1613 \mathrm{~cm}^{-1}$, $1284 \mathrm{~cm}^{-1}$ and $1212 \mathrm{~cm}^{-1}$ after treatment showed deformation of aromatic compound benzoquinoline, alkane (Velayutham et al., 2018) present in dye effluent. The results of spectra were identified according to Roeges and Baas,(1994) who offered a guide to the characteristics of the frequencies band in wave number to identify the functional groups according to the inter and intramolecular interactions created due to vibrational frequencies for the effluent.

To disclose the possible mechanism of effluent degradation, the product of biotransformation of textile effluent was analyzed using UV-visible spectrophotometer between 200 and $800 \mathrm{~nm}$. On comparison with UV- visible absorption spectra before and after treatment, the peak slightly disappeared after treatment, thus revealing the occurrence of biodegradation (Kumar et al., 2014).

Application of traditional effluent treatment requires high cost and continuous input of chemicals is uneconomical and causes environmental damage. Hence, economical and ecofriendly techniques using bacteria can be applied for effluent treatment. Biotreatment offers easy, cheaper and effective alternative for decolorization and degradation of textile effluent. Thus, the present study shows that the bacteria Pseudomonas fluorescence can be cultivated from extracted sugars and can be used as a good microbial source for the treatment of textile effluent. This study has established that bacteria are adaptive to the extracted sugars from Palmyra tuber peels in nature and can degrade the contaminants. It decolorized the textile effluent by degrading compound present in the effluent which cause health problems to humans.

\section{Acknowledgment}

Authors acknowledge the facilities provided by the Department of Biotechnology, Madha Engineering College, Chennai to carry out this research work.

\section{References}

Arapoglou, D., T. Varzakas, A. Vlyssides and C. Israilides: Ethanol production from potato peel waste (PPW). Waste. Manage., 30, 1898-1902 (2010).

Aremu, M.O., O.A. Olu-Arotiowa, S.K. Layokun and B.O. Solomon: Growth of Pseudomonas fluorescence on cassava starch hydrolysate for polyhydroxybutyrate production. J. Apl. Sci. Environ. Manag., 14, 61-66 (2010).

Benjamin, C., P.K. Singh and P.S. Dipuraj: Bio-ethanol production from banana peel by simultaneous saccharification and fermentation process using cocultures Aspergillus niger and Saccharomyces cerevisiae. Int .J. Curr. Microbiol., App. Sci., 3, 84-96 (2014).

Bhattacharyya, S., S. Chakraborty, S. Datta, E. Drioli and C. Bhattacharjee: Production of total reducing sugar (TRS) from acid hydrolysed potato peels by sonication and its optimization.
Environ. Technol., 34,1077-1084 (2013).

Binder, J.B. and R.T. Raines: Simple chemical transformation of lignocellulosic biomass into furans for fuels and chemicals. J. Am. Chem. Soc., 131, 1979-1985(2009).

Binder, J.B. and R.T. Raines: Fermentable sugars by chemical hydrolysis of biomass. Proc. Natl. Acad. Sci., 107, 4516-4521 (2010).

Buzala, K.P., H. Kalinowska, P. Przybysz and E. Małachowska: Conversion of various types of lignocellulosic biomass to fermentable sugars using kraft pulping and enzymatic hydrolysis. Wood. Sci. Technol., 51, 873-885 (2017).

Chaturvedi., V. and P. Verma: An overview of key pretreatment processes employed for bioconversion of lignocellulosic biomass into biofuels and value added products. Biotech., 3, 415-431 (2013).

Chaurasiya, A.K., I. Chakraborty and J. Saha: Value addition of Palmyra palm and studies on the storage life. J. Food. Sci. Technol., 51, 768-773 (2014).

Dadi, A.P., S. Varanasi and C.A. Schall: Enhancement of cellulose saccharification kinetics using an ionic liquid pretreatment step. Biotechnol. Bioeng., 95, 904-910 (2006).

Fetyan, N.A., A.A. Azeiz, I.M. Ismail and T.M. Salem: Biodegradation of Cibacron Red azo dye and industrial textile effluent by Pseudomonas aeruginosa immobilized on Chitosan- $\mathrm{Fe}_{2} \mathrm{O}_{3}$ composite. J. Adv. Biol. Biotechnol., 12, 1-15 (2017).

Giwa, A., U.G. Akpan, P.O. Nkeonye, K.A. Bello and E.G. Kolawole: Solar photocatalytic degradation of acid blue 29. J. Chem. Soc. Nutr., 36, 82-89 (2011).

Hellen, S, D.J., A.M. Turakhia, M.A. Kumar, N. Balaji, S. Selvanaveen, G. Vinodhini and M. Seenuvasan: Bioethanol from saccharificed lignocellulosic rich Aloe vera rinds using Saccharomyces cerevisiae MTCC4779. Energy. Sourc. A, Recovery Util. Environ. Effects, 39, 1347-1352 (2017).

Kilpelainen, I., H. Xie, A. King, M. Granstrom, S. Heikkinen and D.S. Argyropoulos: Dissolution of wood in ionic liquids. J. Agric. Food Chem., 55, 9142-9148(2007).

Kumar, M.A., A. Vijayalakshmi, E.A.R. Lincy, M.D. Palin, M. Seenuvasan, V.V. Kumar and S. Sivanesan: Biotransformation of reactive black HEBL into 3-nitroso-3-azabicyclo (3.2.2) nonane by an acclimated mixed culture. Int. J. Chemtech. Res., 6, 4172-4179 (2014).

Kumar, M.A., V.V. Kumar, R. Ponnusamy, F.P. Daniel, M. Seenuvasan, C.D. Anuradha and S. Sivanesan: Concomitant mineralization and detoxification of acid red 88 by an indigenous acclimated mixed culture. Environ. Prog. Sustain. Energy., 34,1455-1466 (2015).

Kumar, M.A., D.K. Harthy, V.V. Kumar, K.G. Balashri, M. Seenuvasan, D. Anuradha and S. Sivanesan: Detoxification of a triphenylmethane textile colorant using acclimated cells of Bacillus mannanilyticus strain AVS. Environ. Prog. Sustain. Energy., 36, 394-403 (2017).

Kumar, M.A., S. Poonam, V.V. Kumar, G. Baskar, M. Seenuvasan, D. Anuradha and S. Sivanesan: Mineralization of aromatic amines liberated during the degradation of a sulfonated textile colorant using Klebsiella pneumoniae strain AHM. Process. Biochem., 57, 181-189 (2017).

Lange, J.P.: Lignocellulose conversion: An introduction to chemistry process and economics. Biofuel. Bioprod. Biorefin., 1, 39-48 (2007).

Lenihan, P., A. Orozco, E. Oneill, M.N.M. Ahmad, D.W. Rooney and G.M. Walker: Dilute acid hydrolysis of lignocellulosic biomass. Chem. Eng J., 156, 395-403 (2010).

Li, C. and Z.K. Zhao: Efficient acid-catalyzed hydrolysis of cellulose in 
ionic liquid. Adv. Synth. Catal., 349,1847-1850(2007).

Li, C., Q.Wang and Z.K. Zhao: Acid in ionic liquid: An efficient system for hydrolysis of lignocellulose. Green Chem., 10, 177-182 (2008).

Lin, J., X. Zhang, Z. Li and L. Lei: Biodegradation of Reactive blue 13 in a two-stage anaerobic/aerobic fluidized beds system with a Pseudomonas sp. isolate. Bioresour. Technol., 101, 34-40 (2010).

MacFaddin, J. F.: Biochemical Tests for Identification of Medical Bacteria. $2^{\text {nd }}$ Edn., Williams and Wilkins, Baltimore (1980).

Miller, G. L.: Use of dinitrosalicylic acid reagent for determination of reducing sugar. Anal. Chem., 31, 426-428 (1959).

Parte, S., K. Rokade, G. Mali and S. Kudale: Biodegradation of sulfonated aromatic amine by Pseudomonas desmolyticum NCIM 2112. J. Chem. Pharm. Res., 5, 335-339 (2013).

Peters, D.: Rawmaterials. In: White Biotechnology. Advances in Biochemical Engineering/Biotechnology (Eds.: R. Ulber and D. Sell). Springer. Berlin. Heidelberg.,105, 1-30 (2006).

Rinaldi, R., R. Palkovits and F. Schuth: Depolymerization of cellulose using solid catalysts in ionic liquids. Angewandte Chemie., 120, 8167-8170 (2008).

Roeges, N.P. and J.M.A. Baas: A guide to the complete interpretation of infrared spectra of organic structures. John Wiley, Chichester, $p$. $282(1994)$

Severian, D.: Polysaccharides: Structural diversity and functional versatility. $2^{\text {nd }}$ Edn., Marcel Dekker, New York (2008).

Seenuvasan, M., S.J. Sanjayini, M.A. Kumar, G. Vinodhini, J. Hellen Sathya and V.V. Kumar: Cellulase-mediated saccharification of lignocellulosic-rich pseudostem of Musa cavendish for bio-ethanol production by Saccharomyces cerevisiae MTCC 4779. Energy Sourc. A, Recovery Util. Environ. Effects., 39, 570-575 (2017).

Singh, T., A.A. Vaidya, L.A. Donaldson and A.P. Singh: Improvement in the enzymatic hydrolysis of biofuel substrate by a combined thermochemical and fungal pretreatment. Wood. Sci. Technol., 50, 1003-1014 (2016).

Singh, S., B.A. Simmons and K.P. Vogel: Visualization of biomass solubilization and cellulose regeneration during ionic liquid pretreatment of switchgrass. Biotechnol. Bioeng., 104, 68-75 (2009).

Sievers, C., M.B. Valenzuela-Olarte, T. Marzialetti , I. Musin, P.K. Agrawal and C.W. Jones : Ionic-liquid-phase hydrolysis of pine wood. Ind Eng.Chem. Res., 48, 1277-1286 (2009).

Souto, L.R.F., M. Caliari, M.S. Soares, Junior, F.A. Fiorda and M.C. Garcia: Utilization of residue from cassava starch processing for production of fermentable sugar by enzymatic hydrolysis. Food Sci. Technol. (Campinas), 37, 19-24 (2017).

Trevelyan, W.E., R.S. Forrest and J.S. Harrison : Determination of yeast carbohydrates with the anthrone reagent. Nature, 170, 626627(1952).

Vanoye, L., M. Fanselow, J.D. Holbrey, M.P. Atkins and K.R. Seddon: Kinetic model for the hydrolysis of lignocellulosic biomass in the ionic liquid, 1-ethyl-3-methyl-imidazolium chloride. Green Chem., 11, 390-396 (2009)

Velayutham, K., A.K. Madhava, M. Pushparaj, A. Thanarasu, T. Devaraj, K. Periyasamy and S. Subramanian: Biodegradation of Remazol Brilliant Blue R using isolated bacterial culture (Staphylococcus sp. K2204). Environ Technol., 39, 2900-2907 (2018).

Vidhyadevi, T., A. Murugesan, S.S. Kalaivani, M.A Kumar, K.V.T. Ravi, L. Ravikumar, C.D. Anuradha and S. Sivanesan: Optimization of process parameters for removal of reactive yellow dye by low cost Setaria verticillata carbon using response surface methodology: Thermodynamic, kinetic and equilibrium studies. Environ. Prog. Sustain. Energy, 33, 855-865 (2014). 